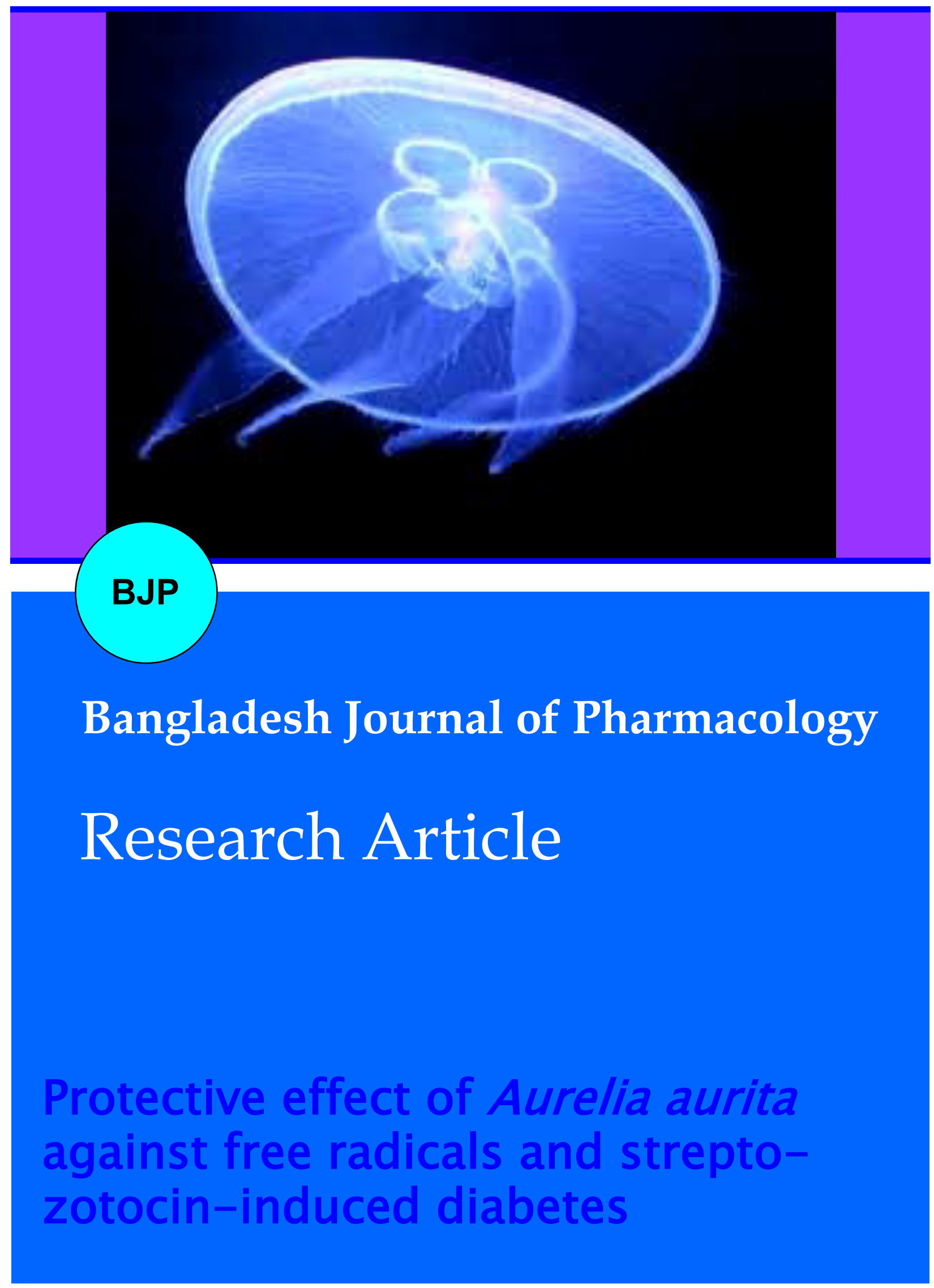




\title{
Protective effect of Aurelia aurita against free radicals and strepto- zotocin-induced diabetes
}

\author{
Mallikarjuna Rao Talluri, Alekhya Ketha, Ganga Rao Battu, Rajananda Swamy Tadi and Vinay \\ Bharadwaj Tatipamula
}

AU College of Pharmaceutical Sciences, Andhra University, Visakhapatnam 530 003, Andhra Pradesh, India.

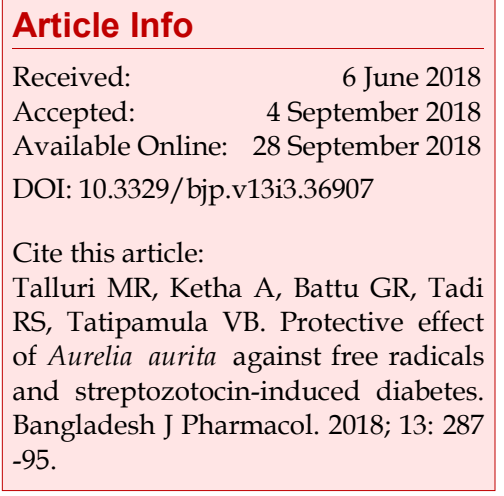

\begin{abstract}
The present work was carried out to identify the anti-oxidant and antidiabetic activities of Aurelia aurita. The chemical profiling analysis showed that it possess different biologically active secondary metabolites like phenols, alakoids, steroids etc. The methanolic extract showed different free radical scavenging activity as ascorbic acid with $\mathrm{IC}_{50}$ values 202, 205, $153 \mu \mathrm{g}$ on $\mathrm{DPPH}$, hydroxyl and superoxide free radicals. The extract significantly reduced the hyperglycemic conditions with percentage of reduction $18.7 \pm 1.3$ to $53.5 \pm 1.5$ of streptozotocin-induced animals and the positive result of invitro aldose reductase enzyme inhibition with $\mathrm{IC}_{50}$ value $163 \mu \mathrm{g}$ suggests that A. aurita have potential to cure the diabetic complications.
\end{abstract}

\section{Introduction}

Natural products are the basic source for the development of therapeutics which has been using in treatment of human diseases since ancient times (Paterson and Anderson, 2005). From the last two centuries, there was tremendous progress in the science and technology and is helping in studies of different diseases' pathology and isolation, development of new drug molecules from natural products to treat the diseases (Newman and Cragg, 2007; Harvey, 2000; Henkel et al., 1999). The scientists are currently working on natural products mainly on terrestrial origins. But, there is ample sources are available in marine origins (Malve, 2016; Kong et al., 2010; Mayer et al., 2010; Jha and Zi-rong, 2004).

In our earlier studies, three marine algae Chaetomorpha antennina, Gracilaria corticata and Ulva faciata from Visakhapatnam coast (Battu et al., 2011) and uncommon moss, Taxithelium napalense broth from Bhitarkanika Island, India were found to have antibacterial, antioxidant and anti-diabetic activities (Tatipamula et al., 2017).
Aurelia aurita is a common jelly fish present all over the world and is a widely studied species. The species is feed on phytoplankton present in oceans, which are made up of different biologically secondary metabolites (Zoccarato et al., 2016). The earlier studies reports that, different phytoplankton possess more biologically active compounds and A. aurita also have different chemical compounds and it host for different microbial community in its body which are possess biologically active metabolites (Ahmed et al., 2017; Leone et al., 2013; Wright et al., 2003). So, the present work carried out on anti-diabetic activity of A. aurita.

\section{Materials and Methods}

\section{Chemicals}

Streptozotocin for diabetes induction was purchased from the Sigma-Aldrich, USA. Anti-diabetic drug metformin (Lupin, India) was purchased from the local market. The other chemicals, reagents used in current research were analytical grade. 


\section{Collection of jellyfish}

The specimens of $A$. aurita were collected from the Rishikonda Beach, Visakhapatnam $\left(17^{\circ} 68^{\prime}\right.$ latitude and $83^{\circ} 21^{\prime}$ longitude), Andhra Pradesh, India in July, 2015. The collected specimens were identified based on the standard literature by Prof. E. Babu, Zoology Department, Andhra University, Visakhapatnam, Andhra Pradesh, India.

\section{Preparation of extract}

The collected material was preserved in methanol and kept at room temperature and dry place for 3 days. The material soaked in methanol was decant by using Whatman filter paper No. 1 and concentrated under pressure to obtain the crude methanol extract.

\section{Chemical screening}

The different qualitative chemical tests were performed to establish the chemical composition profile of A. aurita extract with various standard chemical tests (Trease and Evans, 2002; Rao, 2013).

\section{Total phenolic content assessment}

The phenolic content of the extract was assessed using standard procedure using Folin-Ciocalteau reagent in gallic acid equivalents as $\mathrm{mg} / \mathrm{g}$. The process is on light absorption measurement of the compounds present in the tested extract due to their reaction (color reduction) with tungsten and molybdenum oxides in FolinCiocalteau reagent (Rao, 2013; Singleton and Rossi, 1965).

\section{Total alkaloid content assessment}

The alkaloid content was assessed using bromocresol green solution as atropine equivalents. The assessment was carried out with the selected extract $(1 \mathrm{mg} / 2 \mathrm{~N} \mathrm{HCl}$ $\mathrm{mL}$ ) blended with $5 \mathrm{~mL}$ of phosphate buffer $(0.1 \mathrm{mM}), 5$ $\mathrm{mL}$ of BCG. Then, alkaloid content was extracted with chloroform. The absorbance of color complex in chloroform was measured at $470 \mathrm{~nm}$ (Rao, 2013).

\section{Free radical scavenging activity}

Free radical scavenging activity was carried out on different free radicals like superoxide, hydroxyl and 2,2 -diphenyl-1-picrylhydrazyl (DPPH) free radicals by comparing with the standard drug ascorbic acid (Rao et al., 2013; Rao et al., 2012). The extract was dissolved in at different concentrations in dimethyl sulfoxide for the study and the experiment was repeated thrice, results showed in mean \pm SEM. The percentage inhibition was calculated as $\left(\mathrm{Ao}-\mathrm{A}_{1}\right) / \mathrm{A}_{0} \times 100$.

Where, $A_{0}$ is the absorbance of control; $A_{1}$ is the absorbance with addition of extract/ascorbic acid

The $50 \%$ inhibition concentrations ( $\mathrm{IC}_{50}$ ) were calculated with each concentration of the extract/ascorbic acid was plotted taking concentration on $\mathrm{X}$-axis and percen- tage inhibition on $\mathrm{Y}$-axis.

\section{Superoxide radical scavenging activity}

Superoxide free radical scavenging activity was carried out using standard procedure, which depends on light induced superoxide generation by riboflavin and the corresponding reduction of nitroblue tetrazolium (Mc Cord et al., 1977; Rao et al., 2013; Rao et al., 2012).

\section{Hydroxyl radical scavenging activity}

Hydroxyl free radical scavenging activity was assessed by using standard procedure, which is mainly based on measurement of color intensity of tested extracts on reduction in production of hydroxyl radicals through iron-EDTA solution reaction with dimethyl sulfoxide, ascorbic acid by addition of cold trichloroacetic acid and Nash reagent (Klein et al., 1981).

\section{2,2-Diphenyl-1-picrylhydrazyl (DPPH) radical scaven- ging activity}

The DPPH radical scavenging activity was measured, as color absorbance by tested extract comparing with ascorbic acid. Prior to the measurement, DPPH (0.004\%) solution was prepared using ethanol and incubated for overnight in dark place. On next day, $3 \mathrm{~mL}$ of DPPH solution mixed vigorously with $100 \mu \mathrm{L}$ of different concentrations of extract, then incubated for $30 \mathrm{~min}$ and then measured the absorbance at $517 \mathrm{~nm}$ against control (Braca et al., 2003; Murali et al., 2011).

\section{Selection of animals}

Healthy albino rats of single sex weighing between 180 $250 \mathrm{~g}$, 60-90 aged days were used for the study from Mahaveer Enterprises, Hyderabad, India. They were maintained on a 12 hours light/dark cycle. They were fed with regular grain chow (Rayans Biotechnologies Pvt. Ltd., India).

\section{Toxicity studies}

The albino rat of either sex, were selected into four groups of consisting of 6 animals. They were maintained for one week before the experiment, under room temperature and allowed free access to water and diet. The animals were subjected for acute toxicity study using A. aurita extract at doses 5, 50, 300, $2000 \mathrm{mg} / \mathrm{kg}$ body weight orally in four groups at regular intervals of time for 7 days. During this time, the animals were under observation to note the different conditions like skin changes, morbidity, aggressiveness, oral secretion, sensitivity to sound and pain, respiratory movement and finally their mortality.

\section{Induction of diabetes induction (Tatipamula et al., 2017)}

The animals were induced for diabetes with streptozotocin in normal saline $(0.1 \mathrm{~mol} / \mathrm{L})$ after the overnight fasting. After three days of streptozotocin adminis- 
tration, the blood glucose levels were measured using a glucometer for the blood collected through tail vein puncture (D'Orazio et al., 2005). The animals with blood glucose levels over the $200 \mathrm{mg} / \mathrm{dL}$ were considered as diabetic and used for further study.

\section{Glucose response in normal rat to single dose of $A$.} aurita extract

Normal rats were divided three groups $(n=6)$ : Group I treated as control (normal); Group II was treated with metformin (500 mg/kg body weight) and Group III was treated with methanolic extract of A. aurita (500 $\mathrm{mg} / \mathrm{kg}$ body weight). After the overnight fasting, the control group fed with $10 \mathrm{~mL} / \mathrm{kg}$ body weight of $1 \%$ carboxymethyl cellulose (vehicle) through orally using force-feeding needle; Group II and III were administrated with extract and drug orally. Blood samples were collected through tail vein puncture at $0 \mathrm{~min}$ and after $30 \mathrm{~min}$ of post drug and extract administration to measure the glucose levels at 0, 30, 60, 90 and $120 \mathrm{~min}$ (Nabi et al., 2013; Gupta et al., 2004).

\section{Glucose tolerance test in normal and streptozotocin- induced diabetic animal}

The rats were divided in five groups $(n=6)$ : Group I to IV were normal rats and Group V was diabetic rats. Prior to the experiment, the fasting blood glucose levels were measured to all groups of rats $(0 \mathrm{~min})$, then Group II treated with $10 \mathrm{~mL} / \mathrm{kg}$ body weight of $1 \%$ carboxymethyl cellulose (vehicle), Group III treated with metformin (500 mg/kg body weight), Group IV and $\mathrm{V}$ were treated with methanolic extract of $A$. aurita (500 mg/kg body weight) orally using force-feeding needle. All the groups were administrated with $2 \mathrm{~g} / \mathrm{kg}$ body weight sugar orally except Group I (control/ normal) within $30 \mathrm{~min}$ of vehicle, metformin and methanolic extract of $A$. aurita administration. Then, the blood was collected through tail vein puncture and the glucose levels were measured at 60,90 and $120 \mathrm{~min}$ time intervals using a glucometer (D'Orazio et al., 2005; Orhan et al., 2006; Pandhare et al., 2011).

\section{Hypoglycemic activity}

The rats were divided into five groups $(n=6)$; Group I was normal rats (control), Group II was diabetic rats (negative control) without any treatment, Group III was normal rats treated with $1 \mathrm{~g} / \mathrm{kg}$ methanolic extract of $A$. aurita, Group IV was diabetic rats treated with metformin ( $500 \mathrm{mg} / \mathrm{kg}$ body weight) as positive control and Group V was diabetic rates treated with $1 \mathrm{~g} / \mathrm{kg}$ methanolic extract of $A$. aurita treated daily for 7 days respectively. The fasting blood was collected on $0,1^{\text {st }}$, $3^{\text {rd }}, 5^{\text {th }}$ and $7^{\text {th }}$ days through tail vein puncture to estimate the blood glucose levels using a glucometer. During these days, the body weight of each group animals were estimated. On 7th day after glucose level estimation, the blood from each group animals was collected through retro-orbital plexus under anesthetic conditions (diethyl ether). The collected blood samples were used for the estimation of plasma total cholesterol, triglycerides, high density lipoprotein and low density lipoproteins, aspartate transaminase, alkaline phosphatase, alanine aminotranferase, creatinine, albumin, total protein levels using Span diagnostic kits on semi-auto analyzer. Finally, the rats were sacrificed. The kidneys and liver were separated and stored at $-20^{\circ} \mathrm{C}$ and used for histopathological studies.

\section{Aldose-reductase activity}

Aldose reductase activity was determined for the methanolic extract of A. aurita (Patel and Mishra, 2009). Eyes from the normal rats were separated, washed with saline and transparent lenses free from diseases were pooled. The homogenate $(10 \%)$ was prepared with $0.1 \mathrm{M}$ phosphate buffer (Saline, $\mathrm{pH} 7.4$ ), then homogenate was centrifuged in a refrigerated centrifuge at 5,000 rpm for $10 \mathrm{~min}$ and then the supernatant was separated and kept in ice. The supernatant was used for the determination of aldose reductase activity. The process simply, for $0.1 \mathrm{~mL}$ lens supernatant was added to 0.7 $\mathrm{mL}$ phosphate buffer $(0.067 \mathrm{M}), 0.1 \mathrm{~mL}$ NADPH $(25 \times 10$ $\left.{ }^{-5} \mathrm{M}\right), 0.1 \mathrm{~mL}$ of DL-glyceraldehyde (substrate at $5 \times 10^{-4}$ $\mathrm{M})$ except reference and then finally the solution was made up to $1 \mathrm{~mL}$. When the substrate was added, the enzymatic reaction started and absorbance was recorded for every $30 \mathrm{sec}$ interval up to $3 \mathrm{~min}$ at $340 \mathrm{~nm}$. In the similar way, different concentrations 25, 50, 100, 200 and $400 \mu \mathrm{g} / \mathrm{mL}$ prepared with phosphate buffer saline used for aldose reductase activity. The negative control was prepared with phosphate buffer saline. Percentage inhibition for different concentrations were measured using the formula:

$\%$ Inhibition $=\Delta \mathrm{Abs}$ (Negative control) $-\Delta \mathrm{Abs}$ (Extract) $/ \Delta \mathrm{Abs}$ (Negative control)

$\mathrm{IC}_{50}$ value for the extract was by plotting graph dose concentration versus percentage inhibition

\section{Statistical analysis}

The results were expressed in mean \pm SEM and compared with control group using two-way ANOVA and followed by Dunnett's test. The $p$ value $<0.05$ were considered as significant.

\section{Results}

\section{Chemical analysis}

The chemical analysis of A. aurita methanolic extract showed the presence of alkaloids, carboxilic acids, phenols, proteins, amino acids, saponins, steroids, terpenoids and absence of carbohydrates, coumarins, flavonoids, glycosides, quinones, and tannins (Table I). Based on chemical analysis, the total alkaloid and 


\begin{tabular}{|clc|}
\hline \multicolumn{2}{|c|}{ Table I } \\
\hline \multicolumn{2}{|c|}{$\begin{array}{c}\text { Chemical analysis of Aurelia } \\
\text { tract }\end{array}$} \\
\hline SL. No & Name of chemical tests & methanolic ex- \\
\hline 1 & Alkaloids & Inference \\
2 & Carbohydrates & - \\
3 & Carboxylic acids & + \\
4 & Coumarins & - \\
5 & Flavanoids & - \\
6 & Glycosides & - \\
7 & Phenol compounds & + \\
8 & Proteins and amino acids & - \\
9 & Quinones & + \\
10 & Saponins & + \\
11 & Steroids & - \\
12 & Tannins & + \\
13 & Terpenoids & \\
\hline
\end{tabular}

phenolic contents were assayed for the extract. The amount of phenol compounds and alkaloids were $5.8 \pm$ $0.5 \mathrm{mg} / \mathrm{g}$ and $4.4 \pm 0.7 \mathrm{mg} / \mathrm{g}$ respectively.

\section{Free radical scavenging activity}

The methanol extract of $A$. aurita showed the concentration-dependent scavenging activity, concentration along with ascorbic acid and the activity was directly proportional (Figure 1). The extract showed more activity at $400 / 100 \mu \mathrm{L}$ concentration. The $\mathrm{IC}_{50}$ values for methanol extract of $A$. aurita and ascorbic acid on DPPH, hydroxyl and superoxide free radicals were 202, 278, 205, 110, 153 and $130 \mu \mathrm{g}$. The extract showed better activity on DPPH and superoxide free radicals.

\section{Toxicity studies}

The toxicity studies were carried out on rats at different

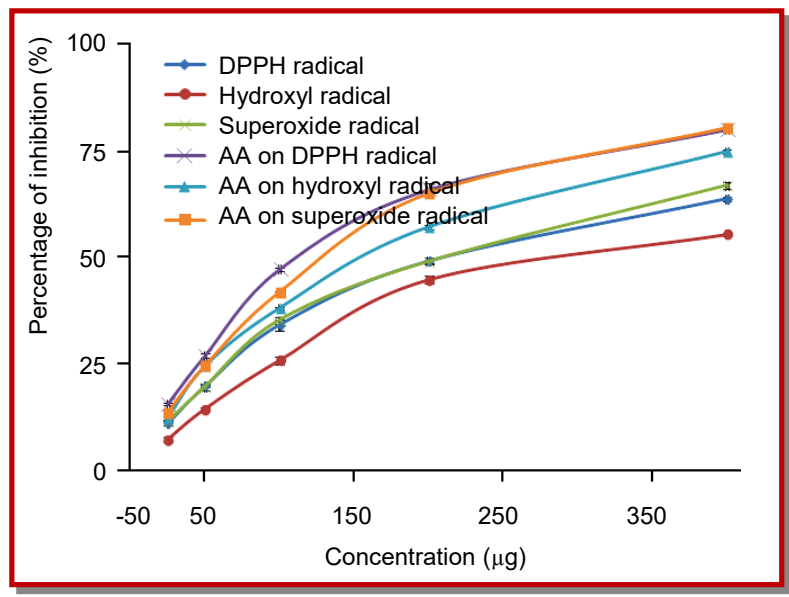

Figure 1: Effect A. aurita extract (single dose) on free radical scavenging activity

concentrations of A. aurita methanolic extract. There was no abnormalities and the mortality were observed at tested doses even at 2,000 mg/ $\mathrm{kg}$. Then, further study was continued on the anti-diabetic activity.

\section{Glucose response in normal rat to single dose of $A$. aurita extract}

In all groups, blood glucose levels were normal at 0 and $30 \mathrm{~min}$ but at $60 \mathrm{~min}$ blood glucose levels were increased because of glucose dosage. In the extract- and metformin-treated groups, blood glucose levels were decreased at 90 and $120 \mathrm{~min}$ compared to normal rats (Group I).

\section{Glucose tolerance test in normal and STZ-induced diabetic animals}

The single dose effect of methanolic extract on normal and diabetic rats were estimated. The blood sugar levels were raised in each group except in diabetic group (Group V), may be because the group animals were already diabetic and there was no significant effect of glucose administration. But, at 90 and $120 \mathrm{~min}$ blood

Table II

Effect of methanolic extract of A. aurita on blood glucose level in different days of experiment

\begin{tabular}{|c|c|c|c|c|c|}
\hline Day & $\begin{array}{l}\text { Control } \\
\text { (Group I) }\end{array}$ & $\begin{array}{c}\text { Untreated dia- } \\
\text { betic } \\
\text { (Group II) }\end{array}$ & $\begin{array}{c}\text { Normal rats treated } \\
\text { with extract } \\
\text { (Group III) }\end{array}$ & $\begin{array}{l}\text { Diabetic rats treated } \\
\text { with metformin } \\
\text { (Group IV) }\end{array}$ & $\begin{array}{c}\text { Diabetic rats treated } \\
\text { with extract } \\
(\text { Group V) }\end{array}$ \\
\hline 0 & $91.2 \pm 1.5$ & $255.0 \pm 1.3$ & $89.7 \pm 1.6$ & $247.5 \pm 3.5$ & $254.5 \pm 1.3$ \\
\hline 1 & $91.5 \pm 1.6$ & $237.7 \pm 1.3$ & $90.8 \pm 0.8$ & $232.0 \pm 1.1$ & $234.2 \pm 1.6$ \\
\hline 3 & $90.2 \pm 1.7$ & $235.0 \pm 2.2$ & $\begin{array}{r}89.5 \pm 0.4 \\
(61.9 \pm 0.4)^{\mathrm{a}}\end{array}$ & $\begin{array}{c}182.5 \pm 1.8 \\
(22.3 \pm 1.2)^{\mathrm{a}}\end{array}$ & $\begin{array}{r}190.8 \pm 1.3 \\
(18.7 \pm 1.3)^{\mathrm{a}}\end{array}$ \\
\hline 5 & $90.2 \pm 1.5$ & $240.2 \pm 3.0$ & $\begin{array}{r}87.3 \pm 1.7 \\
(63.6 \pm 0.8)^{\mathrm{a}}\end{array}$ & $\begin{array}{r}131.0 \pm 2.4 \\
(45.5 \pm 0.6)^{\mathrm{a}}\end{array}$ & $\begin{array}{r}153.0 \pm 1.7 \\
(36.2 \pm 1.2)^{\mathrm{a}}\end{array}$ \\
\hline 7 & $89.8 \pm 1.9$ & $241.2 \pm 2.3$ & $\begin{array}{r}86.0 \pm 1.9 \\
(64.3 \pm 1.0)^{\mathrm{b}}\end{array}$ & $\begin{array}{r}100.3 \pm 1.4 \\
(58.4 \pm 0.5)^{\mathrm{a}}\end{array}$ & $\begin{array}{c}112.0 \pm 2.9 \\
(53.5 \pm 1.5)^{\mathrm{b}}\end{array}$ \\
\hline
\end{tabular}


Table III

\begin{tabular}{|c|c|c|c|c|c|}
\hline \multicolumn{6}{|c|}{ Effect of methanolic extract of $A$. aurita on different plasma parameters } \\
\hline $\begin{array}{l}\text { Name of the plasma pa- } \\
\text { rameter }\end{array}$ & $\begin{array}{l}\text { Control } \\
\text { (Group I) }\end{array}$ & $\begin{array}{l}\text { Untreated } \\
\text { diabetic } \\
\text { (Group II) }\end{array}$ & $\begin{array}{c}\text { Normal rats treated } \\
\text { with extract } \\
\text { (Group III) }\end{array}$ & $\begin{array}{l}\text { Diabetic rats treated } \\
\text { with metformin } \\
(\text { Group IV) }\end{array}$ & $\begin{array}{c}\text { Diabetic rats treated } \\
\text { with extract } \\
(\text { Group V) }\end{array}$ \\
\hline AST (IU/L) & $46 \pm 0.2$ & $103 \pm 0.6$ & $48 \pm 1.3$ & $50 \pm 0.8$ & $62 \pm 0.7$ \\
\hline ALT (IU/L) & $22 \pm 0.0$ & $83 \pm 0.1$ & $26 \pm 0.5$ & $24 \pm 0.4$ & $51 \pm 1.3$ \\
\hline $\operatorname{ALP}(\mathrm{IU} / \mathrm{L})$ & $60 \pm 0.1$ & $185 \pm 1.7$ & $66 \pm 0.7$ & $57 \pm 0.4$ & $72 \pm 1.5$ \\
\hline Creatinine (mg/dL) & $0.6 \pm 0.0$ & $1.8 \pm 0.0$ & $0.7 \pm 0.8$ & $0.6 \pm 0.3$ & $0.7 \pm 0.3$ \\
\hline Albumin (g/dL) & $4.2 \pm 0.9$ & $2.4 \pm 0.7$ & $4 \pm 0.2$ & $4 \pm 0.3$ & $3.8 \pm 0.1$ \\
\hline Total protein $(\mathrm{g} / \mathrm{dL})$ & $6 \pm 0.4$ & $3.5 \pm 0.3$ & $6 \pm 0.3$ & $6.2 \pm 0.1$ & $5.4 \pm 0.3$ \\
\hline Total cholesterol (mg/dL) & $60 \pm 1.2$ & $150 \pm 0.9$ & $73 \pm 0.8$ & $70 \pm 1.7$ & $85 \pm 0.5$ \\
\hline Triglycerides (mg/dL) & $42 \pm 0.9$ & $175 \pm 1.3$ & $50 \pm 1.4$ & $45 \pm 0.6$ & $63 \pm 0.3$ \\
\hline LDL (mg/dL) & $30 \pm 0.3$ & $138 \pm 0.2$ & $36 \pm 0.7$ & $35 \pm 1.3$ & $47 \pm 0.5$ \\
\hline HDL (mg/dL) & $64 \pm 0.2$ & $35 \pm 0.4$ & $58 \pm 0.3$ & $60 \pm 0.9$ & $56 \pm 1.3$ \\
\hline Data were mean \pm SEM & & & & & \\
\hline
\end{tabular}

glucose levels measurement showed the decline in blood glucose levels. Group I (normal rats), Group II (treated with vehicle) showed equal response. Group IV almost showed same response as Group I and Group II at $120 \mathrm{~min}$ measurement. The Group V rats showed decline in the blood glucose levels from 0 to $120 \mathrm{~min}$ but at $120 \mathrm{~min}$ it was little bit higher than the other groups.

\section{Hypoglycemic activity}

Anti-diabetic activity of the methanolic extract of $A$. aurita studied through different ways on normal and diabetic rats. Finally, hypoglycemic activity was studied for 7 days on streptozotocin-induced diabetic animals, the variations in blood glucose levels were observed in different groups (Table II). The blood glucose levels in Group II animals were high, in Groups IV and $\mathrm{V}$ were very high as Group II animals but during and end of the study blood glucose levels were gradually decreased because Group IV was treated with standard drug metformin and Group $\mathrm{V}$ was treated with methanolic extract of A. aurita. The percentage of reduction in blood glucose levels of Group III animals were constant, that indicate while normal rats treated with extract didn't show any alteration in blood glucose levels but diabetic animals treated with metformin and methanolic extract of $A$. aurita showed gradual increase in percentage of reduction in blood glucose levels from day 3 to day 7 , i.e. $22.3 \pm 1.2$ to $58.4 \pm 0.5$ in group IV, $18.7 \pm 1.3$ to $53.5 \pm 1.5$ in Group V, at the end almost the blood glucose levels became normal. At the same time the body weights of different groups were recorded. The body weight of normal rats were increased and diabetic rats losses weight because of no treatment, but the animals treated with extract and metformin lost some weight up to day 3 , then gradually recovered from loss of weight (data not shown).

The methanolic extract of $A$. aurita was restored the altered different plasma parameters like TC, TG, HDL, LDL, AST, ALP, ALT, creatinine, albumin, total protein (Table III). The plasma parameters were normal conditions in group I and III, but in Group IV and V the parameters were tiny high compared to them, this may indicate if the treatment can prolong parameters can be normal as Group I.

The effect of methanolic extract of $A$. aurita was assessed with aldose reductase enzyme using DLglyceraldehyde as substrate and quercetin as standard drug (Figure 2). The extract showed dose-dependent inhibitory activity on aldose reductase enzyme. The extract showed the inhibitory activity almost along with quercetin. The $\mathrm{IC}_{50}$ values for methanolic extract of $A$. aurita and quercetin were found to be 163 and $212 \mu \mathrm{g}$ respectively.

The histopathological studies of liver and pancreas showed the differences in structural variations in normal, untreated diabetic and diabetic treated with metformin and methanolic extract of A. aurita (Figure 3 ). There were a surge was observed in size and nuclei of hepatocytes and large vacuoles were also observed in diabetic rats, the reduction of hepatocytes may be due to the oxidation of cell membrane because of free radicals, it leads to reduced cytosol/nuclei ratio. These leads to cellular necrosis and alteration of liver biomarker enzymes. But, these characteristics were less or normal in normal, metformin-treated and A. aurita extract treated groups, may be because the extract of $A$. aurita showed potent antioxidant activity on free radicals and successfully restored the altered biomarker enzyme' levels due to diabetes (Figure 3). 


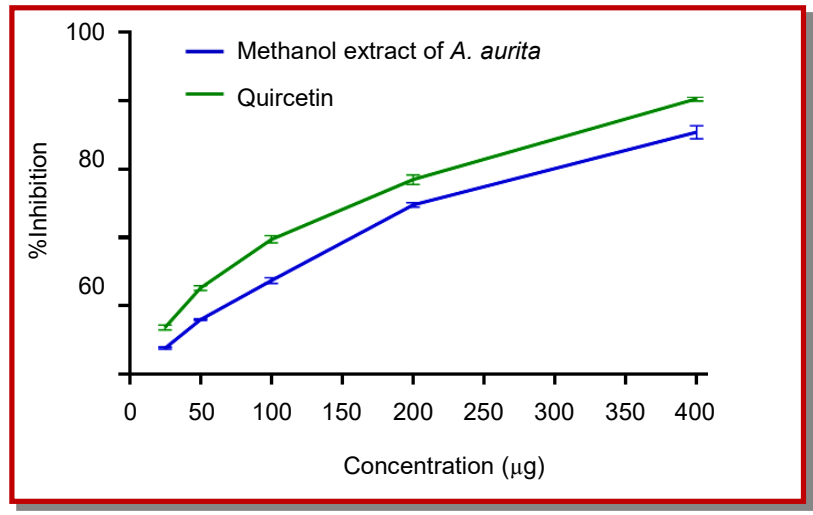

Figure 2: Effect of A. aurita extract on percentage inhibition of aldose reductase

\section{Discussion}

The present work carried out and identified the presence of different biological active compounds like alkaloids, phenolics, saponins, steroids etc. (Fernando et al., 2016; Farvin and Jacobsen, 2013; Yao et al., 2012; Guven et al., 2010) on chemical profile analysis of methanolic extract of $A$. aurita. Based on chemical profiling, the extract of A. aurita was evaluated for its anti-oxidant and anti-diabetic activity. The tested extract showed dose-dependent free radicals scavenging activity and results were comparable with standard drug ascorbic acid. The generation of free radicals will occur through different biological metabolisms. The free radical were unstable ions and like be pair with other atoms, in this process they react with stable atoms and destabilizes it and then again forms a new free radical (Bedwell et al., 1989; Cohen, 1977). The formation of free radical in the body is an chain reaction, then that process they effect the cellular metabolisms and damages to cell membranes (Lipids) and finally leads to diseases (Stadtman and Levine, 2000; Marnett, 2000). The tested extract showed the more activity against superoxide free radical, which is most generate free radical and precursor for different free radicals like hydroperoxyl and hydroxyl radicals (McCord et al., 1977; Bielski and Cabelli, 1996).

The extract treated normal and diabetic animals showed good tolerance against glucose over dose and extract showed good anti-diabetic activity against streptozotocin-induced diabetic rats. Diabetes is a chronic disease, increases the blood glucose levels due to the insufficient production of insulin or decrease in

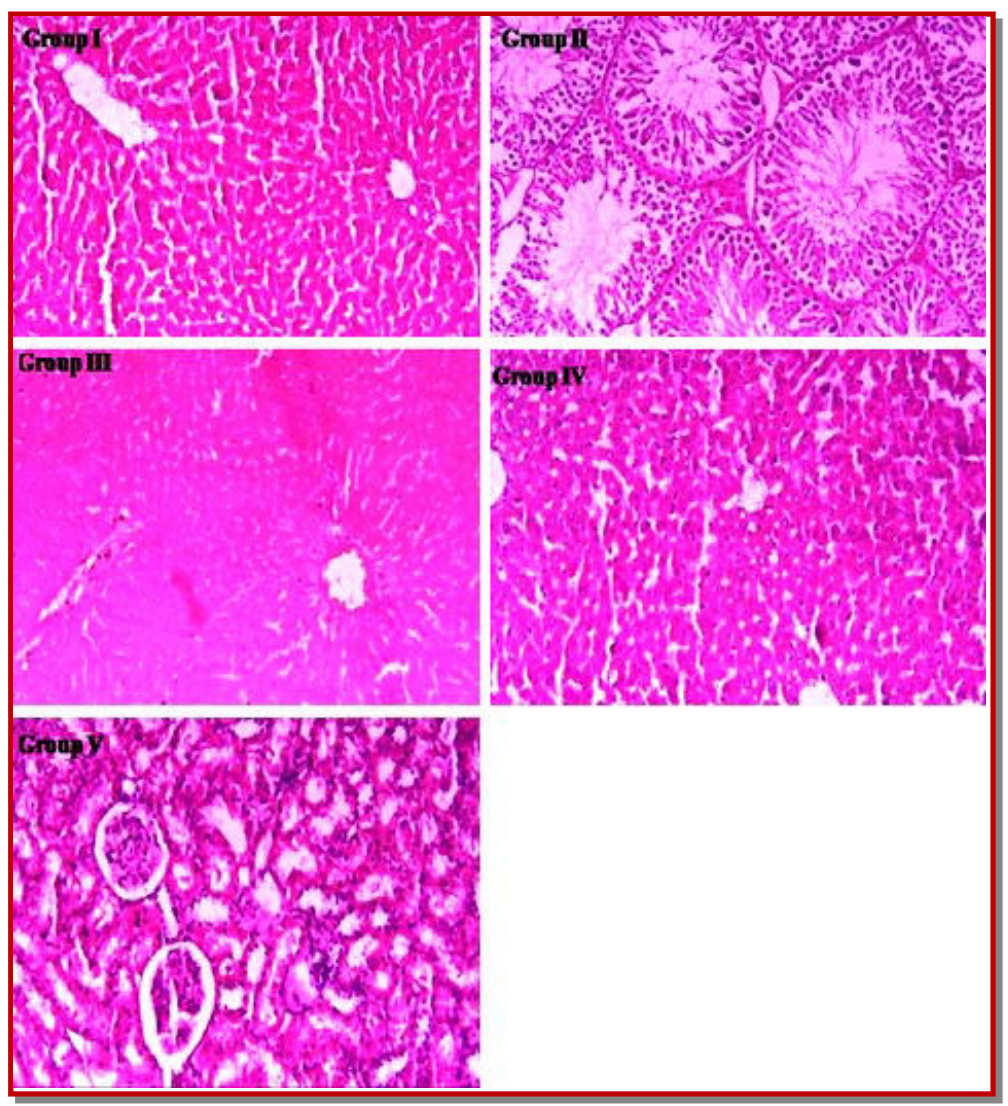

Figure 3: Histopathological changes of different groups' liver tissue in STZ-induced anti-diabetic activity. Group I- Control (Normal rats); Group II-Untreated diabetic; Group III- Normal rats treated with extract; Group IV-Diabetic rats treated with metformin; Group V-Diabetic rats treated with extract 
response of body cells to insulin i.e. insulin is main transporter for the digested energy food (glucose) from blood to cells. The glucose is energy source for cells, inadequate and decrease in response of cells to insulin leads to hyperglycemia in blood and on long term conditions leads to different complications (Papatheodorou et al., 2016) to the body and finally leads to death. In the present study, STZ-induced diabetic rats showed the high blood glucose levels, variations in different plasma parameters like AST, ALT, ALP, creatinin, albumin, total protein, total cholesterol, triglycerides, LDL and HDL and the histopathological studies of pancreas and liver showed inflammation and structural variation (Yeom et al., 2016; Zadhoush et al., 2015; Association, 2010). The structural and functional changes in the liver and pancreas may leads to over production of different free radicals and may cause failure of different organs due to oxidative stress and further complications (Talluri et al., 2016; Ajuwon et al., 2014; Schuppan and Kim, 2013; Zamin Jr et al., 2002). But, the metformin and methanolic extract of $A$. aurita treated animals showed good recovery from the raised blood glucose levels, altered plasma parameters and structural restoration of the liver and pancreas. The in vitro aldose reductase activity of tested extract showed good inhibition of aldose reductase enzyme, aldose reductase is an enzyme mainly present in eyes, works on formation of fructose under normal glycemic conditions, but at hyperglycemic conditions glucose flux will occur through polyol pathway leads to glaucoma, cataracts, diabetic retinopathy (Cheng and González, 1986). The current study results provide the significant contribution to the recent research and development studies in identification of new biologically active compounds from different sources. In recent times, there were many reports about presence of biologically active compounds from terrestrial medicinal plants (Altemimi et al., 2017; Wilson and Brimble, 2009) and marine sources like algae and others (Malve, 2016; Kong et al., 2010; Jha and Zi-rong, 2004) on different chronic and acute diseases and their complications. The further studies could be worth for bio guided isolation of active metabolites from $A$. aurita and different marine sources.

\section{Conclusion}

A. aurita showed the presence of different biological active compounds like alkaloids, phenolics, saponins, steroids etc in it and significantly make well the streptozotocin-induced diabetes rats and showed free radical scavenging activity. The active metabolite in $A$. aurita may be individually or synergistically showed the activities, further research will be needed to know the individual active metabolites or combinational.

\section{Ethical Issue}

The acute toxicity study was conducted for extract of $A$. aurita as per Organization for Economic Co-operation and Development (OECD) guidelines (OECD, 2001) and regulations of the Institutional Animal Ethics Committee.

\section{Conflict of Interest}

There is no conflict of interested.

\section{Acknowledgement}

The authors are thankful to Prof. E. Babu, Zoology Department, Andhra University for confirmation of collected specimen and AU College of Pharmaceutical Sciences, Andhra University for providing necessary facilities to complete the present work.

\section{References}

Ahmed SH, Eissa DM, Hassan MK, Abaas OA. Ameliorative effect of the Aurelia aurita venom on the murine ehrlish ascites carcinoma-induced hepatotoxicity and nephrotoxicity. Int J Adv Res. 2017; 5: 1167-78.

Ajuwon OR, Oguntibeju OO, Marnewick JL. Amelioration of lipopolysaccharide induced liver injury by aqueous rooibos (Aspalathus linearis) extract via inhibition of pro-inflammatory cytokines and oxidative stress. BMC Complement Altern Med. 2014; 14: 392.

Altemimi A, Lakhssassi N, Baharlouei A, Watson DG, Lightfoot DA. Phytochemicals: Extraction, isolation, and identification of bioactive compounds from plant extracts. Plants 2017; 6: 42.

Association AD. Diagnosis and classification of diabetes mellitus. Diabetes Care. 2010; 32: S62-69.

Battu GR, Ethadi SR, Murthy PP, Praneeth VSD, Rao TM. Invitro Antibacterial activity and preliminary phytochemical screening of three algae from Visakhapatnam coast, Andhra Pradesh, India. Int J Pharm Pharm Sci. 2011; 3: 399-401.

Bedwell S, Dean RT, Jessup W. The action of defined oxygencentred free radicals on human low-density lipoprotein. Biochem J. 1989; 262: 707-12.

Bielski BHJ, Cabelli DE. Superoxide and hydroxyl radical chemistry in aqueous solution. In: Active oxygen in chemistry. Foote CS, Valentine JS, Greenberg A, Liebman JF (eds). Vol 2. Structure energetics and reactivity in chemistry series. Springer Dordrecht, 1996, pp 66-104.

Braca A, Fico G, Morelli I, De Simone F, Tome F, De Tommasi $\mathrm{N}$. Anti-oxidant and free radical scavenging activity of flavonol glycosides from different Aconitum species. J Ethnopharmacol. 2003; 86: pp 63-67.

Cheng HM, González RG. The effect of high glucose and oxidative stress on lens metabolism, aldose reductase, and senile cataractogenesis. Metab Clin Exp. 1986; 35: 10-14. 
Cohen G. An acetaldehyde artifact in studies of the interaction of ethanol with biogenic amine systems: The oxidation of ethanol by ascorbic acid. J Neurochem. 1977; 29: 761-62.

D'Orazio P, Burnett RW, Fogh-Andersen N, Jacobs E, Kuwa K, Külpmann WR, Larsson L, Lewnstam A, Maas AH, Mager G, Naskalski JW, Okorodudu AO. Approved IFCC recommendation on reporting results for blood glucose (abbreviated). Clin Chem. 2005; 51: 1573-76.

Farvin SKH, Jacobsen C. Phenolic compounds and antioxidant activities of selected species of seaweeds from Danish coast. Food Chem. 2013; 138: 1670-81.

Fernando IP, Kim M, Son KT, Jeong Y, Jeon YJ. Anti-oxidant activity of marine algal polyphenolic compounds: A mechanistic approach. J Med Food. 2016; 19: 615-28.

Gupta S, Kataria M, Gupta PK, Murganandan S, Yashroy RC. Protective role of extracts of neem seeds in diabetes caused by streptozotocin in rats. J Ethnopharmacol. 2004; 90: 185-89.

Guven KC, Percot A, Sezik E. Alkaloids in marine algae. Mar Drugs. 2010; 8: 269-84.

Harvey A. Strategies for discovering drugs from previously unexplored natural products. Drug Discov Today. 2000; 5: 294-300.

Henkel T, Brunne RM, Müller H, Reichel F. Statistical investigation into the structural complementarity of natural products and synthetic compounds. Angew Chem Int Ed. 1999; 38: 643-47.

Jha RK, Zi-rong X. Biomedical compounds from marine organisms. Mar Drugs. 2004; 2: 123-46.

Klein SM, Cohen G, Cederbaum AI. Production of formaldehyde during metabolism of dimethyl sulphoxide by hydroxyl radical-generating system. Biochemistry 1981; 20: 6006-12.

Kong DX, Jiang YY, Zhang HY. Marine natural products as sources of novel scaffolds: Achievement and concern. Drug Discov Today. 2010; 15: 884-86.

Leone A, Lecci RM, Durante M, Piraino S. Extract from the zooxanthellate jellyfish Cotylorhiza tuberculata modulates gap junction intercellular communication in human cell cultures. Mar Drugs. 2013; 11: 1728-62.

Malve H. Exploring the ocean for new drug developments: Marine pharmacology. J Pharm Bioallied Sci. 2016; 8: 83-91.

Marnett LJ. Oxyradicals and DNA damage. Carcinogenesis 2000; 21: 361-70.

Mayer AM, Glaser KB, Cuevas C, Jacobs RS, Kem W, Little RD, Mcintosh JM, Newman DJ, Potts BC, Shuster DE. The odyssey of marine pharmaceuticals: A current pipeline perspective. Trends Pharmacol Sci. 2010; 31: 255-65.

McCord JM, Michelson AM, Fridovich I. Superoxide and superoxide dismutases. London, Academic Press, 1977, 320.

Murali A, Ashok P, Madhavan V. In vitro anti-oxidant activity and HPTLC studies on the roots and rhizomes of Smilax zeylanica L. (Smilacaceae). Int J Pharm Pharm Sci. 2011; 3: 192 -95 .

Nabi SA, Kasetti RB, Sirasanagandla S, Tilak TK, Kumar MVJ,
Rao CA. Antidiabetic and antihyperlipidemic activity of Piper longum root aqueous extract in STZ induced diabetic rats. BMC Complement Altern Med. 2013; 13: 37.

Newman DJ, Cragg GM. Natural products as sources of new drugs over the last 25 years. J Nat Prod. 2007; 70: 461-77.

Organisation for Economic Co-operation and Development (OECD). 2001. Acute Oral ToxicityFixedDose.Procedure.https://ntp.niehs.nih.gov/iccvam/ SuppDocs/FedDocs/OECD/OECD_GL420.pdf.

Orhan N, Aslan M, Orhan DD, Ergun F, Yesilada E. In-vivo assessment of antidiabetic and anti-oxidant activities of grapevine leaves (Vitisvini fera) in diabetic rats. J Ethnopharmacol. 2006; 108: 280-86.

Ortholand JY, Ganesan A. Natural products and combinatorial chemistry: Back to the future. Curr Opin Chem Biol. 2004; 8: 271-80.

Patel M, Mishra S. Aldose reductase inhibitory activity and anticataract potential of some traditionally acclaimed antidiabetic medicinal plants. Orient Pharm Exp Med. 2009; 9: 245-51.

Pandhare RB, Sangameswaran B, Mohite PB, Khanage SG. Antidiabetic activity of aqueous leaves extract of Sesbaniasesban (L) Merr. instreptozotocin induced diabetic rats. Avicenna J Med Biotech. 2011; 3: 37-43.

Papatheodorou K, Papanas N, Banach M, Papazoglou D, Edmonds M. Complications of Diabetes, 2016. J Diabetes Res. 2016.

Paterson I, Anderson EA. The renaissance of natural products as drug candidates. Science 2005; 310: 451-53.

Rao BG, Rao YV, Rao TM. Hepatoprotective and anti-oxidant capacity of Melochia corchorifolia extracts. Asian Pac J Trop Med. 2013; 6: 537-43.

Rao TM, Rao BG, Rao YV. Anti-oxidant activity of Spilanthes acmella extracts. Int J Phytopharm. 2012; 3: 216-20.

Rao TM. Biological and preliminary phytochemical evaluation of three folklore medicinal plants, Melochia corchorifolia L, Chrozophora rottleri (Geiseler) A. Juss. Ex Spreng and Spilanthes acmellaL., PhD Thesis, Andhra University, Visakhapatnam, Andhra Pradesh, India, 2013.

Schuppan D, Kim YO. Evolving therapies for liver fibrosis. The J Clin Invest. 2013; 123: 1887.

Singleton VL, Rossi JA. Colorimetry of total phenolics with phosphomolybdic-phosphotungstic acid reagents. AJEV. 1965; 16: 144-58.

Stadtman ER, Levine RL. Protein oxidation. Ann N Y Acad Sci. 2000; 899: 191-208.

Talluri MR, Tadi RS, Battu GR. Thioacetamide-induced acute liver toxicity in rats treated with Balanites roxburghii extracts. J Acute Dis. 2016; 5: 413-18.

Tatipamula VB, Killari KN, Ketha A, Vedula GS. Taxithelium napalense acts against free radicals and diabetes mellitus. Bangladesh J Pharmacol. 2017; 12: 197-203.

Trease G, Evans SM. Pharmacognosy. 15th ed. Bailer Tindal, London, Elsevier Publisher, 2002, pp 23-67. 
Wilson ZE, Brimble MA. Molecules derived from the extremes of life. Nat Prod Rep. 2009; 26: 44-71.

Wright AD, Osterhage C, König GM. Epicoccamide, a novel secondary metabolite from a jellyfish-derived culture of Epicoccum purpurascens. Org Biomol Chem. 2003; 1: 50710.

Yao Y, Cheng XZ, Wang LX, Wang SH, Ren G. Major phenolic compounds, anti-oxidant capacity and antidiabetic potential of rice bean (Vignaum bellata L.) in China. Int J Mol Sci. 2012; 13: 2707-16.

Yeom E, Byeon H, Lee SJ. Effect of diabetic duration on hemorheological properties and platelet aggregation in streptozotocin-induced diabetic rats. Sci Rep. 2016; 6: 21913.

Zadhoush F, Sadeghi M, Pourfarzam M. Biochemical changes in blood of type 2 diabetes with and without metabolic syndrome and their association with metabolic syndrome components. J Res Med Sci. 2015; 20: 763-70.

Zamin Jr I, Mattos AAD, Perin C, Ramos GZ. The importance of AST/ALT rate in nonalcoholic steatohepatitis diagnosis. Arquivos de gastroenterologia. 2002; 39: 22-26.

Zoccarato L, Celussi M, Pallavicini A, Umani SF. Aurelia aurita Ephyrae reshape a coastal microbial community. Front Microbiol. 2016; 7: 749. 